\title{
Reliability assessment of the post-limit stiffness and ductility of steel joints
}

\author{
Helena Gervásio $^{\mathrm{a}, *}$, L. Simões da Silva ${ }^{\mathrm{b}}$, L. Borges ${ }^{\mathrm{b}}$ \\ a GIPAMB Consulting Engineers Ltd., Lisbon, Portugal \\ b Civil Engineering Department, University of Coimbra, Coimbra, Portugal
}

\begin{abstract}
Steel joints must exhibit sufficient ductility for safe structural behaviour. This is especially true for partial-strength steel joints, whereby the nonlinear response of the joint plays an important part in the overall response of the structure. Uncertainty in joint response, particularly beyond the elastic limit of the moment-rotation curve, naturally leads to a probabilistic treatment of the ductility of steel joints. It is the objective of the present paper to compare a direct probabilistic approach with simulation techniques using the Monte-Carlo method both at the component and joint level, in the context of the component method, with the aim of establishing safe limits for the ductile behaviour of the steel joints.

(C) 2003 Published by Elsevier Ltd.
\end{abstract}

Keywords: Steel joints; Reliability; Monte-Carlo method; Ductility

\section{Introduction}

Current state-of-the-art models for steel and composite joints are based on the so-called "component method" [1], whereby a joint is modelled as an assembly of springs and rigid links. Steel joints may present a wide range of geometries, with different number of bolt rows and connecting parts. Because of this variety of configurations, joint models may range from a simple three-component model, as in a welded beam-to-column joint, to a complex $n$-component model in the case of an extended end-plate multiple bolt-row beam-to-column joint, as illustrated in Fig. 1. Despite the differences in these models, any joint can be subdivided into three different zones: tension, compression and shear. Within each region, several elemental

\footnotetext{
* Corresponding author. Tel.: +351-21-793-8502; fax: +351-21-793-8460.

E-mail address: helena@lisboa.gipac.pt (H. Gervásio).
} 

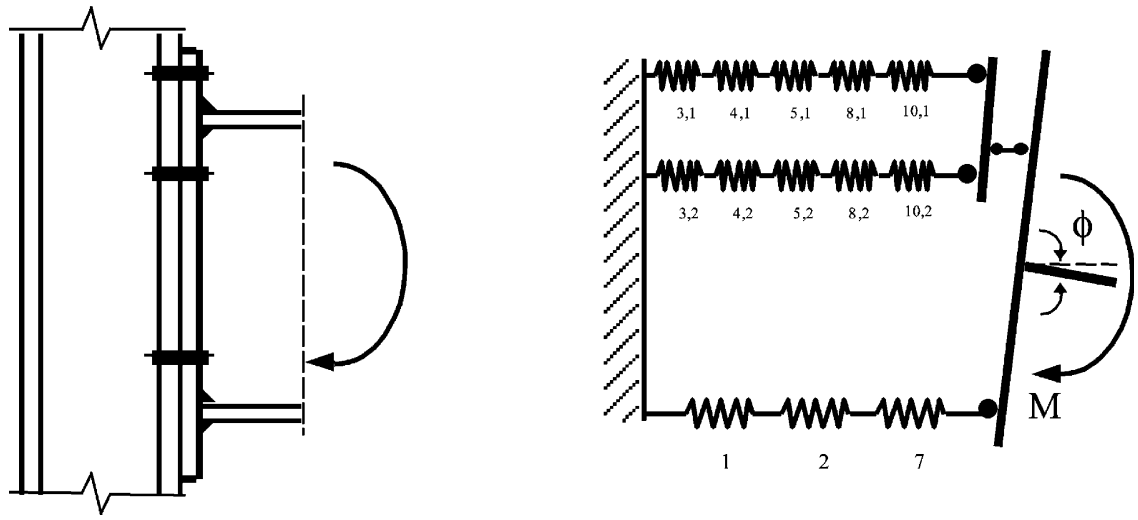

Fig. 1. Mechanical model for extended end-plate beam-to-column connection.

parts (components) contribute to the overall response of the joint, namely: (i) column web panel in shear, (ii) column web in compression, (iii) column web in tension, (iv) column flange in bending, (v) end-plate in bending, (vi) flange cleat in bending, (vii) beam flange in compression, (viii) beam web in tension or compression, (ix) plate in tension or compression, (x) bolts in tension, (xi) bolts in shear, (xii) bolts in bearing and (xiii) welds.

Each component (spring) is characterized by a nonlinear force-displacement curve, hereafter taken as a bi-linear approximation [2], typified in Fig. $2\left(k_{\mathrm{e}}, k_{\mathrm{p}}, F^{\mathrm{Y}}\right.$, $\Delta^{\mathrm{y}}$ and $\Delta^{\mathrm{f}}$ denote the initial elastic stiffness, the post-limit stiffness, the strength, the yield displacement and the collapse displacement of the component, respectively). Depending on their collapse/yield displacement ratio, the components may be classified into three main groups: (a) components with high ductility, (b) components with limited ductility and (c) components with brittle failure.

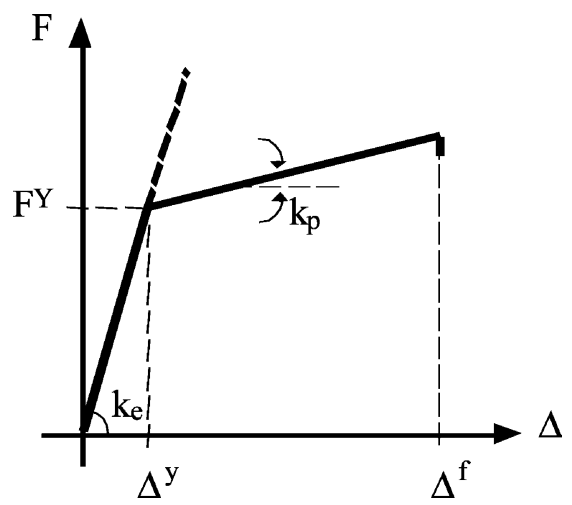

Fig. 2. Typical bi-linear force-displacement diagram for generic component. 
Practical applications in terms of code regulations are already available [3] allowing a designer to assess the strength and stiffness of a significant number of steel and composite joint configurations. In many situations, however, strength and stiffness are not by themselves sufficient to ensure safety. In particular, for partialstrength joints, enough ductility must be available to avoid brittle failure of the joint [4]. Currently, no reliable estimates of the post-limit stiffness of the various components are available in the literature, the usual practice being to consider a plastic plateau for ductile components [5]. Additionally, no estimates are also available for the failure deformation of the components. Given that small variations of the post-limit stiffness (in particular for the critical component) may result in large variations of the maximum rotation of the joint, it is the purpose of the present paper to assess the influence of the various component properties on the available ductility of the joint.

\section{Uncertainty in the behaviour of joints}

\subsection{Introduction}

According to the Joint Committee on Structural Safety [6], uncertainty in the different parameters of a system can be assessed in many ways: (i) Level 0 methods correspond to pure deterministic analyses where uncertainty is taken into account by introducing a global safety coefficient which is empirically calculated; (ii) Level 1 methods are based on average or characteristic values for each variable, each affected by adequate partial safety coefficients, thus corresponding to a semi-probabilistic approach; (iii) Level 2 methods correspond to a simplified probabilistic analysis whereby the probabilistic distribution of each random variable is simply assessed through the corresponding mean and standard deviation, while dependence between variables is taken into account using a matrix of covariance; and finally (iv) Level 3 methods take all joint probability distributions into consideration, using pure probabilistic methods.

Determination of the moment-rotation response of steel joints requires three basic steps:

(i) selection of the relevant (active) components from a global list of components (20 different components currently codified, for example, in Part 1.8 of EC3);

(ii) evaluation of the force-deformation response of each component;

(iii) assembly of the active components for the evaluation of the moment-rotation response of the joint, using a representative mechanical model (Fig. 1).

The first step requires no uncertainty considerations, since the active components are a straightforward choice from the joint configuration and loading type. For the latter two, however, uncertainty may be assessed in different ways, as described 
above. In the framework of a probabilistic analysis, both steps are described in detail in the following paragraphs.

\subsection{Probabilistic assessment of component response}

The various components constitute in itself substructures that, among other factors, depend on the material properties of steel. Assuming that the bi-linear approximation of Fig. 2 represents the force-displacement response of any joint component, four properties suffice to fully define it: initial elastic stiffness, $k_{\mathrm{e}}(E)$, yield force, $F^{\mathrm{Y}}\left(f_{\mathrm{y}}\right)$, post-limit stiffness, $k_{\mathrm{p}}\left(f_{\mathrm{y}}, E_{\mathrm{h}}\right)$, and collapse displacement, $\Delta^{\mathrm{f}}\left(f_{\mathrm{y}} f_{\mathrm{u}}, E_{\mathrm{h}}\right)$, where the major dependence on steel properties is highlighted for each component property. In order to assess the influence of component characterization on the global response of joints, a probabilistic description for each variable is adopted. While fairly accurate estimates already exist in the literature for the quantification of $k_{\mathrm{e}}$ and $F^{\mathrm{Y}}$ for the various components [3], little or no guidance at all is available on the characterization of $k_{\mathrm{p}}$ and $\Delta^{\mathrm{f}}$ [7]. Accordingly, two alternative possibilities are considered:

(i) deterministic characterization of initial elastic stiffness and yield force, represented by its unfactored design value and probabilistic description of the remaining two properties, post-limit stiffness and failure displacement, according to a chosen probability distribution around some plausible mean value and standard deviation (Fig. 3);

(ii) probabilistic description of yield force to assess the influence of variability of yield stress of steel, known to exhibit a big difference between nominal and actual yield stress [8].

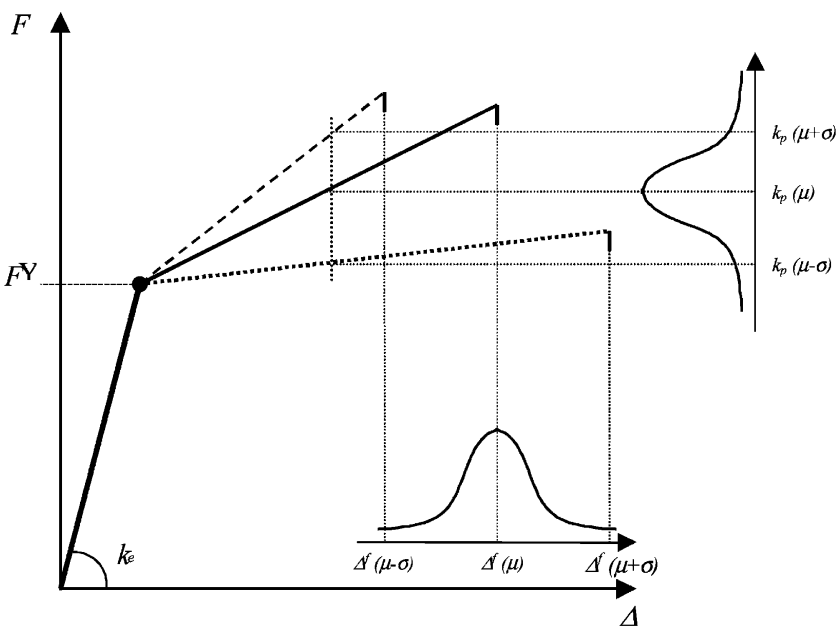

Fig. 3. Probabilistic characterization of component response. 


\subsection{Modelling of joint response}

The third step, component assembly, is carried out by solving the mechanical model of Fig. 1. To compare alternative methodologies, two probabilistic approaches are implemented. The first consists of a Monte-Carlo simulation technique [9], whereby solution of the component model is systematically carried out in a deterministic way to yield a locus of statistically valid solutions that provide a probabilistic description of joint response. Because the solution of the component model of Fig. 1 requires a nonlinear procedure (given the nonlinear behaviour of the springs (components)), the corresponding numerical implementation is illustrated in the flowchart of Fig. 4. The solution is carried out under a standard Newton-Raphson scheme under load control. Care is taken to identify and output all component notable points, namely component yield points and failure of the joint.

The second approach consists of a direct probabilistic procedure [9], whereby the probability descriptors are directly obtained from the probability distribution of the component properties. Because of its analytical nature, solution of the

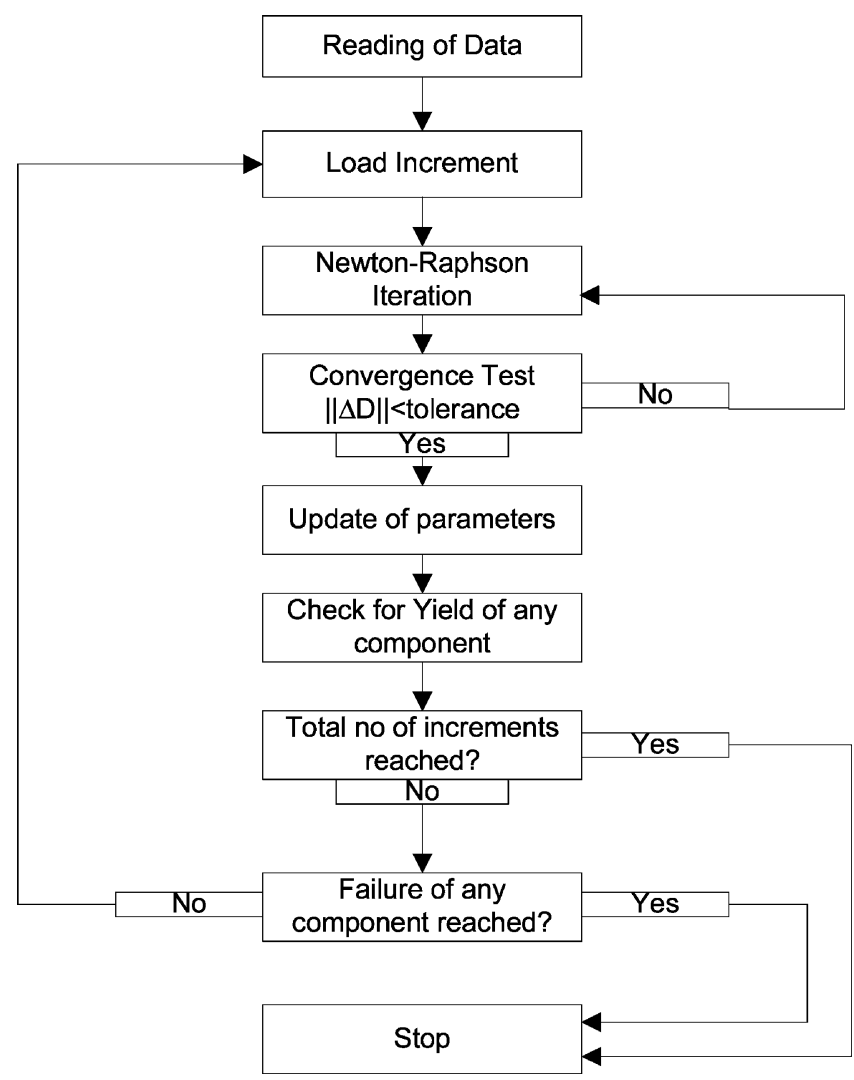

Fig. 4. Numerical calculation of nonlinear $M-\theta$ curve. 
component models is best carried out using a simplified analytical procedure whereby the moment-rotation response is directly obtained from closed-form analytical expressions. Full details of this procedure are available in [10].

\section{Application of direct probabilistic approach to the evaluation of joint ductility}

As referred above, model BL-BL [10] was chosen to obtain the analytical solutions for the moment-rotation response of a steel joint, reproduced in Eqs. (1)-(4), where $k_{\mathrm{e} j}(j=\mathrm{t}, \mathrm{c})$ denotes the initial stiffness of the tensile and compressive zones, respectively, $k_{\mathrm{p} j}(j=\mathrm{t}, \mathrm{c})$ represents the post-limit stiffness of the tensile and compressive zones, respectively, $P_{j}^{B}$ is defined as twice the yield force of the tensile or compressive zones, $q_{i}$ denote the various degrees of freedom (joint rotation and component deformation) and $z$ is the lever arm of the joint.

(i) Fundamental solution

$$
M=\frac{z^{2} k_{\mathrm{ec}} k_{\mathrm{et}}}{2\left(k_{\mathrm{ec}}+k_{\mathrm{et}}\right)} \operatorname{sen}\left(2 q_{1}\right) \quad q_{2}=0 \quad q_{3}=0
$$

(ii) Nonlinear solution in $q_{2}$

$$
\begin{aligned}
& M=\frac{z k_{\mathrm{ec}} k_{\mathrm{et}}}{k_{\mathrm{ec}}+k_{\mathrm{et}}}\left[z \operatorname{sen} q_{1}-\frac{2 z k_{\mathrm{ec}} k_{\mathrm{et}} \operatorname{sen} q_{1}-P_{\mathrm{c}}^{\mathrm{B}}\left(k_{\mathrm{ec}}+k_{\mathrm{et}}\right)}{2\left[k_{\mathrm{pc}}\left(k_{\mathrm{ec}}+k_{\mathrm{et}}\right)+k_{\mathrm{ec}} k_{\mathrm{et}}\right]}\right] \cos q_{1} \\
& 1-\cos q_{2}=\frac{2 z k_{\mathrm{ec}} k_{\mathrm{et}} \operatorname{sen} q_{1}-P_{\mathrm{c}}^{\mathrm{B}}\left(k_{\mathrm{ec}}+k_{\mathrm{et}}\right)}{4 L_{\mathrm{c}}\left[k_{\mathrm{pc}}\left(k_{\mathrm{ec}}+k_{\mathrm{et}}\right)+k_{\mathrm{ec}} k_{\mathrm{et}}\right]} \\
& q_{3}=0
\end{aligned}
$$

(iii) Nonlinear solution in $q_{3}$

$$
\begin{aligned}
& M=\frac{z k_{\mathrm{ec}} k_{\mathrm{et}}}{k_{\mathrm{ec}}+k_{\mathrm{et}}}\left[z \operatorname{sen} q_{1}-\frac{2 z k_{\mathrm{ec}} k_{\mathrm{et}} \operatorname{sen} q_{1}-P_{\mathrm{t}}^{\mathrm{B}}\left(k_{\mathrm{ec}}+k_{\mathrm{et}}\right)}{2\left[k_{\mathrm{pt}}\left(k_{\mathrm{ec}}+k_{\mathrm{et}}\right)+k_{\mathrm{ec}} k_{\mathrm{et}}\right]}\right] \cos q_{1} \\
& q_{2}=0 \\
& 1-\cos q_{3}=\frac{2 z k_{\mathrm{ec}} k_{\mathrm{et}} \operatorname{sen} q_{1}-P_{\mathrm{t}}^{\mathrm{B}}\left(k_{\mathrm{ec}}+k_{\mathrm{et}}\right)}{4 L_{\mathrm{t}}\left[k_{\mathrm{pt}}\left(k_{\mathrm{ec}}+k_{\mathrm{et}}\right)+k_{\mathrm{ec}} k_{\mathrm{et}}\right]}
\end{aligned}
$$

(iv) Nonlinear solution in $q_{2}$ and $q_{3}$

$$
\begin{aligned}
& M=\frac{z k_{\mathrm{ec}} k_{\mathrm{et}}}{k_{\mathrm{ec}}+k_{\mathrm{et}}}\left[z \operatorname{sen} q_{1}-2 L_{\mathrm{c}}\left(1-\cos q_{2}\right)-2 L_{\mathrm{t}}\left(1-\cos q_{3}\right)\right] \cos q_{1} \\
& 1-\cos q_{2}=\frac{2 z k_{\mathrm{ec}} k_{\mathrm{et}} \operatorname{sen} q_{1}-P_{\mathrm{c}}^{\mathrm{B}}\left(k_{\mathrm{ec}}+k_{\mathrm{et}}\right)-4 L_{\mathrm{t}} k_{\mathrm{ec}} k_{\mathrm{et}}\left(1-\cos q_{3}\right)}{4 L_{\mathrm{c}}\left[k_{\mathrm{pc}}\left(k_{\mathrm{ec}}+k_{\mathrm{et}}\right)+k_{\mathrm{ec}} k_{\mathrm{et}}\right]} \\
& 1-\cos q_{3}=\frac{2 z k_{\mathrm{ec}} k_{\mathrm{et}} k_{\mathrm{pc}} \operatorname{sen} q_{1}-k_{\mathrm{ec}} k_{\mathrm{et}}\left(P_{\mathrm{t}}^{\mathrm{B}}-P_{\mathrm{c}}^{\mathrm{B}}\right)-P_{\mathrm{t}}^{\mathrm{B}}\left(k_{\mathrm{ec}}+k_{\mathrm{et}}\right) k_{\mathrm{pc}}}{4 L_{\mathrm{t}}\left[k_{\mathrm{ec}} k_{\mathrm{et}}\left(k_{\mathrm{pc}}+k_{\mathrm{pt}}\right)+\left(k_{\mathrm{ec}}+k_{\mathrm{et}}\right) k_{\mathrm{pc}} k_{\mathrm{pt}}\right]}
\end{aligned}
$$


Eqs. (1)-(4) yield $M$ as a system of functions of several variables, considered as random variables, symbolically denoted by $M=g_{k}\left(X_{1}, X_{2}, \ldots, X_{n}\right)$. The probability distribution of $M$, represented by its moments - mean and variance, will be derived from the probability distributions (moments) of the basic random variables. Following standard probability concepts [9], expanding $g_{k}\left(X_{1}, X_{2}, \ldots, X_{n}\right)$ in Taylor series about the mean values $\mu_{x_{1}}, \mu_{x_{2}}, \ldots, \mu_{x_{n}}$, yields

$$
\begin{aligned}
M= & g_{k}\left(\mu_{x_{1}}, \mu_{x_{2}}, \ldots, \mu_{x_{n}}\right)+\sum_{i=1}^{n}\left(X_{i}-\mu_{x_{i}}\right) \frac{\partial g}{\partial X_{i}}+\frac{1}{2} \sum_{i=1}^{n} \sum_{j=1}^{n}\left(X_{i}-\mu_{x_{i}}\right) \\
& \times\left(X_{j}-\mu_{x_{j}}\right) \frac{\partial^{2} g}{\partial X_{i} \partial X_{j}}+\cdots
\end{aligned}
$$

Truncating Eq. (5) and assuming independent random variables, the mean and standard deviation are approximately given by

$$
\begin{aligned}
& E(M) \simeq g_{k}\left(\mu_{x_{1}}, \mu_{x_{2}}, \ldots, \mu_{x_{n}}\right)+\frac{1}{2} \sum_{i=1}^{n}\left(\frac{\partial^{2} g}{\partial X_{i}^{2}}\right) \operatorname{Var}\left(X_{i}\right) \\
& \operatorname{Var}(M) \simeq \sum_{i=1}^{n}\left(\frac{\partial g}{\partial X_{i}}\right)^{2} \operatorname{Var}\left(X_{i}\right)
\end{aligned}
$$

or, as a first order approximation for the mean value,

$$
E(M) \simeq g_{k}\left(\mu_{x_{1}}, \mu_{x_{2}}, \ldots, \mu_{x_{n}}\right) .
$$

\section{Application of Monte-Carlo simulation to the evaluation of joint ductility}

\subsection{Sampling of independent random variables}

One of the main tasks in a simulation procedure is the generation of random numbers from prescribed probability distributions. This can be achieved using a random generator available in any computer according to the following procedure: (i) generation of a uniformly distributed random number between 0 and 1, and (ii) application of appropriate transformations in order to obtain the corresponding random number with the specified probability distribution.

The Box and Muller method was adopted in this paper, and consists of a direct transformation of two random, independent and uniform variables, $U_{1}$ and $U_{2}$, ]0,1[, into two random, independent and standard variables, $X_{1}$ and $X_{2}$ :

$$
\begin{aligned}
& X_{1}=\sqrt{-2 \ln U_{1}} \cos \left(2 \pi U_{2}\right) \\
& X_{2}=\sqrt{-2 \ln U_{1}} \sin \left(2 \pi U_{2}\right)
\end{aligned}
$$

Both the independence and the randomness of the generated numbers should always be checked after this procedure. 


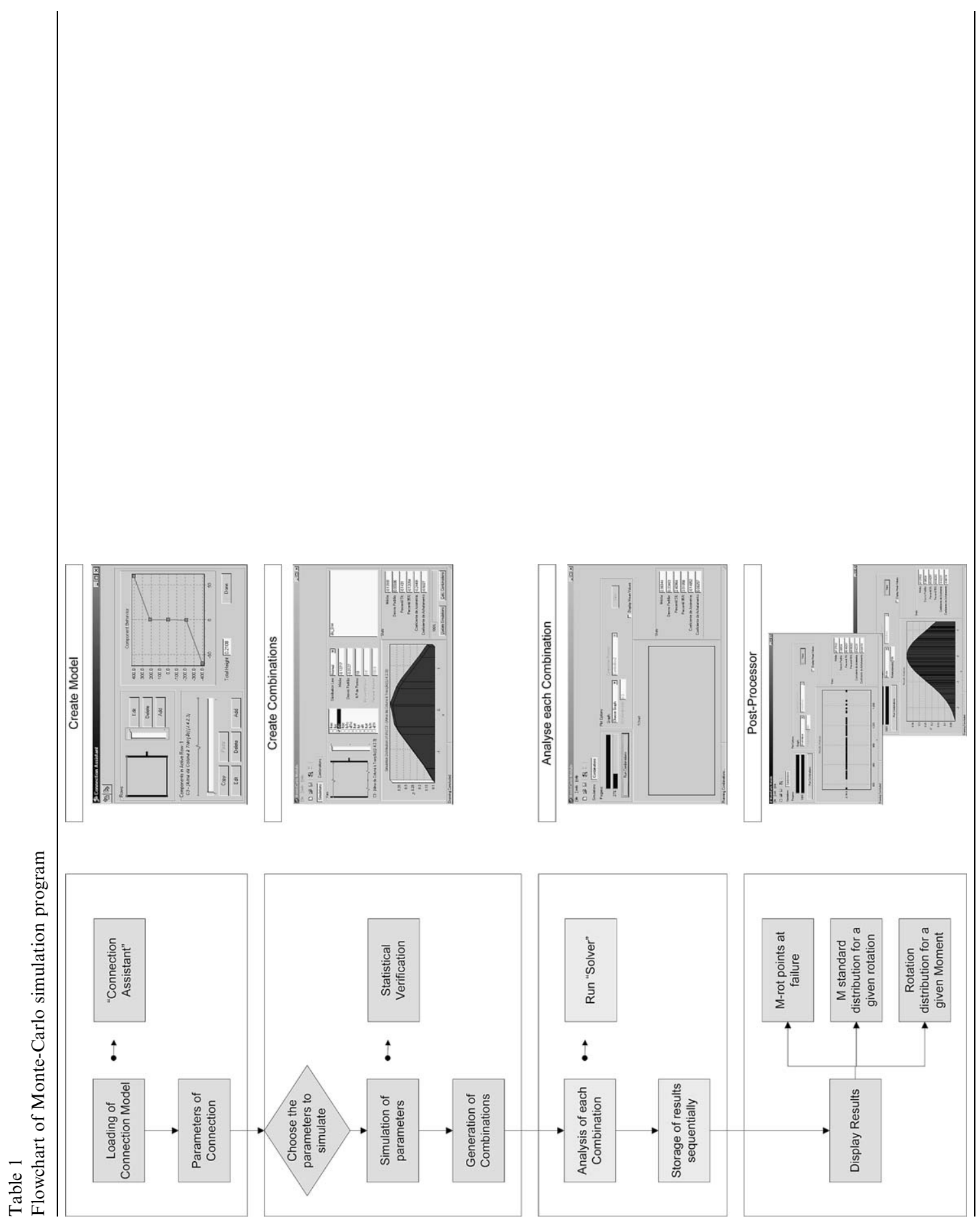



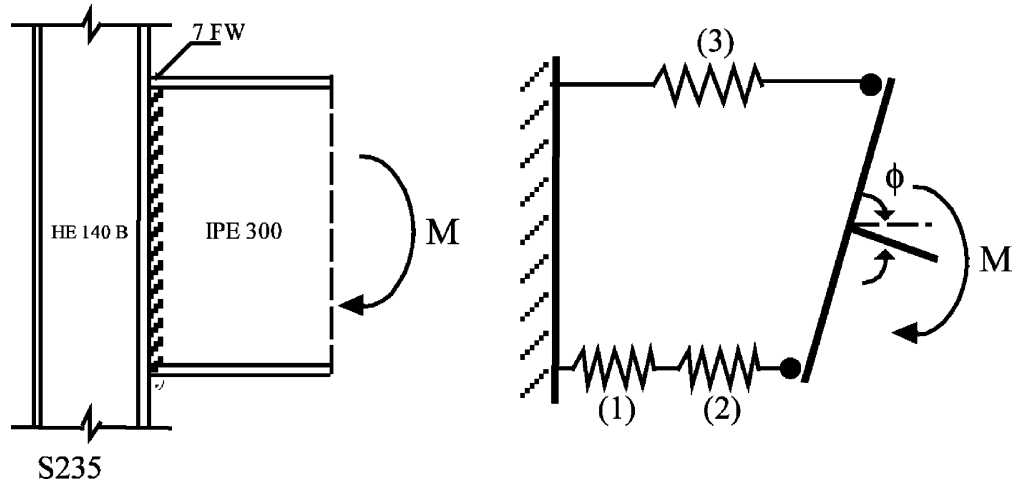

Fig. 5. Beam-to-column welded steel connection (Klein 105.011).

\subsection{Monte-Carlo procedure}

Monte-Carlo simulation involves repeating a simulation process, using in each simulation a particular set of values of the random variables generated in accordance with the corresponding probability distributions. By repeating the process, a sample of solutions is obtained. A sample from the Monte-Carlo simulation is similar to a sample of experimental observations. Therefore, the results of MonteCarlo simulation may be treated statistically.

The application of the Monte-Carlo procedure explained above for the evaluation of the moment-rotation response of steel joints is described in the following:

(i) For a total number of components, $n, r \leq 4 n$ random variables representing the selected random component properties $\left(k_{\mathrm{e}}, F^{\mathrm{Y}}, k_{\mathrm{p}}, \Delta^{\mathrm{f}}\right)$ are considered.

(ii) For each random variable $r, m_{r}$ values are generated using the procedure of Section 4.1.

(iii) For each simulation, the $m_{r}$ values for each random variable are combined, resulting in a sample containing $m$-dimensional values, where

$$
m=\prod_{j=1}^{r} m_{j}
$$

Table 2

Component characterization

\begin{tabular}{llllll}
\hline Component & $F_{\text {norm }}^{\mathrm{Y}}(\mathrm{kN})$ & $F_{\text {real }}^{\mathrm{Y}}(\mathrm{kN})$ & $k_{\mathrm{e}}(\mathrm{kN} / \mathrm{m})$ & $k_{\mathrm{p}}(\mathrm{kN} / \mathrm{m})$ & $\Delta^{\mathrm{y}}(\mathrm{mm})$ \\
\hline 1 & 159.67 & 218.10 & $3.608 \times 10^{5}$ & $6.013 \times 10^{4}$ & 0.443 \\
2 & 182.32 & 249.04 & $1.803 \times 10^{6}$ & $4.624 \times 10^{3}$ & 0.101 \\
3 & 182.32 & 249.04 & $1.803 \times 10^{6}$ & $4.624 \times 10^{3}$ & 0.101 \\
\hline
\end{tabular}


Table 3

Statistical characterization of random variables

\begin{tabular}{lll}
\hline Component & $k_{\mathrm{p}}(\mathrm{kN} / \mathrm{m})$ & $\sigma$ \\
\cline { 2 - 3 } & $\mu$ & $3.00 \times 10^{3}$ \\
\hline Tension & $4.624 \times 10^{3}$ & $4.00 \times 10^{4}$ \\
Shear & $6.013 \times 10^{4}$ & $3.00 \times 10^{3}$ \\
Compression & $4.624 \times 10^{3}$ & \\
\hline
\end{tabular}

(iv) Using the appropriate mechanical model (Fig. 1) for the chosen joint configuration, and the deterministic procedure explained in Section 2.3, $m$ momentrotation curves are obtained for each simulation.

(v) Steps (ii)-(iv) are repeated to generate $s$ independent simulations.

(vi) Finally, direct probabilistic assessment is carried out on the $s$ available simulations for the desired indicators (failure rotation or sequence of yielding of the various components, for example).

The implementation of the Monte-Carlo procedure is illustrated in Table 1.

\section{Example: beam-to-column welded steel joint}

In order to illustrate the procedures described above, one joint configuration was chosen from the database SERICON II (Klein 105.011) [11], corresponding to a

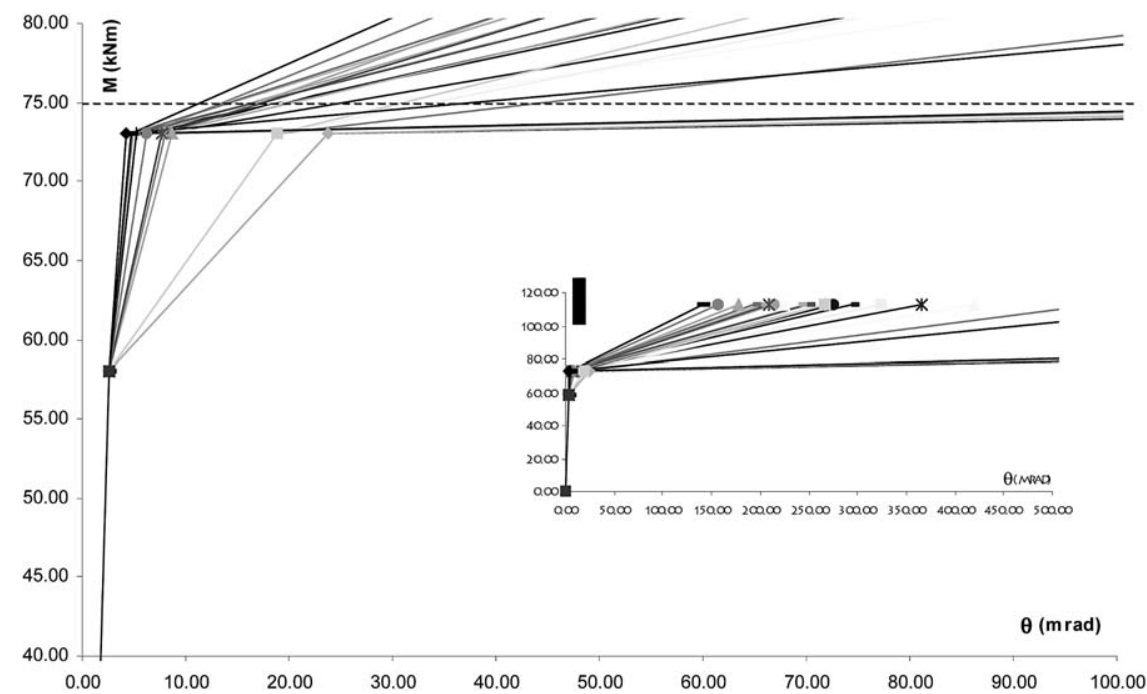

Fig. 6. Probabilistic moment-rotation curves for random post-limit stiffness (Monte-Carlo method). 
Table 4

Moment resistance results for both methods (case 1)

\begin{tabular}{lll}
\hline & $\mu_{M}$ & $\sigma_{M}$ \\
\hline Direct procedure & 80.85 & 4.28 \\
Monte-Carlo simulations & 76.48 & 1.82 \\
\hline
\end{tabular}

beam-to-column welded steel connection, described in Fig. 5, which was tested in pure bending by Klein at the University of Innsbruck in 1985.

Table 2 reproduces the different properties for the various components evaluated, where possible, according to EC3 [3], using either nominal or real (measured) values of yield stress of steel. Application of the EC3 procedures in a deterministic way leads to an initial stiffness of $K_{\text {init }}=21566 \mathrm{kNm} / \mathrm{rad}$ and a moment resistance of $M_{\mathrm{Rd}, \text { nom }}=46.19 \mathrm{kNm}$ or $M_{\mathrm{Rd} \text {, real }}=63.10 \mathrm{kNm}$.

Firstly, to explore the influence of the post-limit stiffness, only these properties are assumed as random variables, as shown in Table 3.

Using the direct probabilistic approach, the mean value of the moment for a given rotation is obtained from Eq. (8) substituting the values of the random variables by their mean value. From Eq. (7), the standard deviation is given by

$$
\sigma_{M}^{2}=\left[\left(\frac{\partial g}{\partial k_{\mathrm{pc}}}\right)_{\mu_{k \mathrm{pc}}}\right]^{2} \times \sigma_{k_{\mathrm{pc}}}^{2}+\left[\left(\frac{\partial g}{\partial k_{\mathrm{pc}}}\right)_{\mu_{k_{\mathrm{pt}}}}\right]^{2} \times \sigma_{k_{\mathrm{pt}}}^{2}
$$

The Monte-Carlo method yields the results in Fig. 6.

The results from both approaches for a rotation of $30 \mathrm{mrad}$ are summarized in Table 4.

Secondly, to assess the influence of the variability of yield stress of steel, the yield strength of the critical component $\left(f_{\text {cws }}\right)$ is also assumed as a random variable (see Table 5).

The standard deviation is now explicitly given by Eq. (13), one additional term being included to account for the randomness of the yield strength of the column

Table 5

Statistical characterization of random variables

\begin{tabular}{llllll}
\hline Component & $F^{\mathrm{Y}}(\mathrm{kN})$ & & & $k_{\mathrm{p}}(\mathrm{kN} / \mathrm{m})$ \\
\cline { 2 - 2 } \cline { 5 - 5 } & $\mu$ & & & & $\sigma$ \\
\hline Tension & 249.04 & & & $4.624 \times 10^{3}$ & $3.00 \times 10^{3}$ \\
Shear & 200.00 & 25 & & $6.013 \times 10^{4}$ & $4.00 \times 10^{4}$ \\
Compression & 249.04 & & & $4.624 \times 10^{3}$ & $3.00 \times 10^{3}$ \\
\hline
\end{tabular}




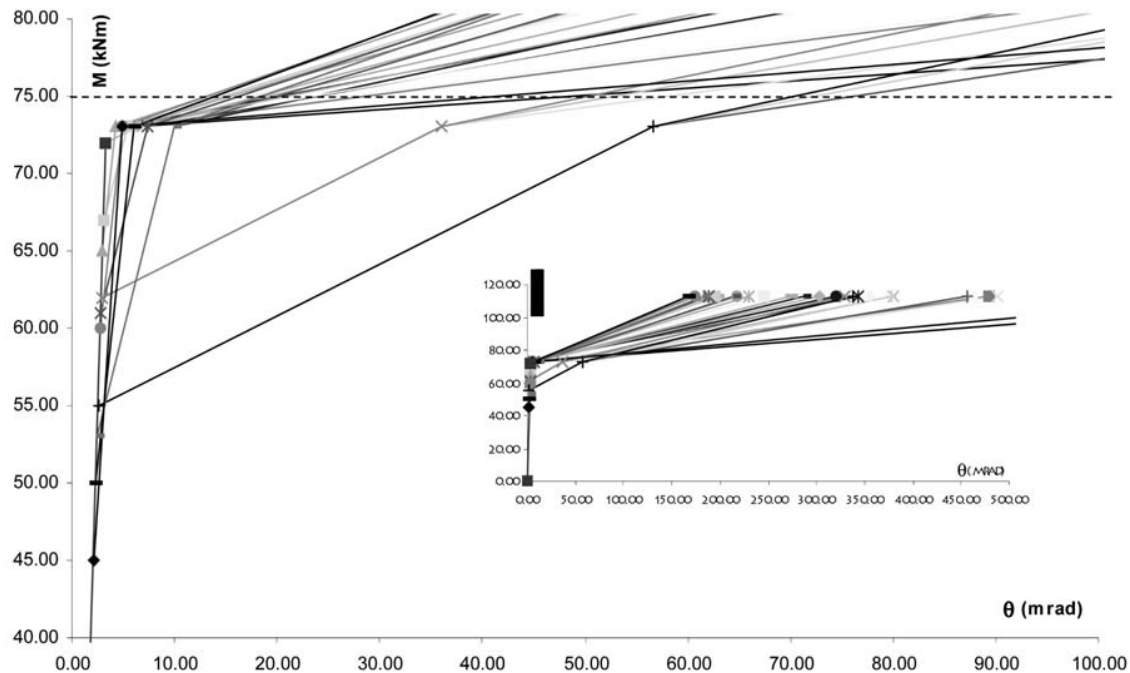

Fig. 7. Probabilistic moment-rotation curves for welded joint.

web in shear:

$$
\begin{aligned}
\sigma_{M}^{2}= & {\left[\left(\frac{\partial g}{\partial k_{\mathrm{pc}}}\right)_{\mu_{\mathrm{kc}}}\right]^{2} \times \sigma_{k_{\mathrm{pc}}}^{2} } \\
& +\left[\left(\frac{\partial g}{\partial k_{\mathrm{pc}}}\right)_{\mu_{k_{\mathrm{pt}}}}\right]^{2} \times \sigma_{k_{\mathrm{pt}}}^{2}+\left[\left(\frac{\partial g}{\partial F_{\mathrm{C}}^{\mathrm{Y}}}\right)_{\mu_{F_{\mathrm{C}}^{\mathrm{Y}}}}\right]^{2} \times \sigma_{P_{\mathrm{C}}^{\mathrm{B}}}^{2}
\end{aligned}
$$

Similar application of the two methods leads to the results in Fig. 7 and Table 6.

Fig. 8 illustrates the histogram of rotation $\theta$ for a fixed moment $M$ of $75 \mathrm{kNm}$, which highlights a significant scatter of possible rotations.

\section{Conclusions}

The simple example presented in this paper illustrates the change in failure mode that occurs from the combination of two random variables, leading to failure of the stronger (in statistical sense) component. This aspect is crucial in steel and

Table 6

Moment resistance results for both methods (case 2)

\begin{tabular}{lll}
\hline & $\mu_{M}$ & $\sigma_{M}$ \\
\hline Direct procedure & 80.85 & 4.31 \\
Monte-Carlo simulations & 76.46 & 2.84 \\
\hline
\end{tabular}




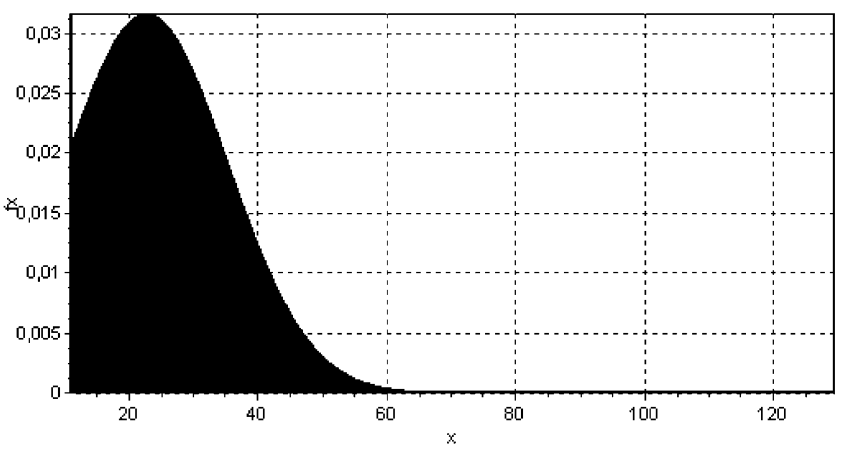

Fig. 8. Histogram of rotation $\theta$ for a fixed moment $M$ of $75 \mathrm{kNm}$.

composite joints because a brittle component like the bolts or the welds may become critical, leading to unexpected brittle failure of the joint.

Current Eurocode specifications [3] do not consider this possibility, in spite of the excellent but limited assessment carried out by Weynand [12]. In fact, by assuming that the post-limit stiffness of all components is zero, in clear contrast with the real stable behaviour of ductile components such as the T-stub or the column web panel in shear, brittle components (bolts or welds) may reach their collapse loads for smaller rotations. The safe use of the semi-rigid concept completely depends on a clear understanding of these aspects.

\section{References}

[1] Weynand K, Jaspart JP, Steenhuis M. The stiffness model of revised Annex J of Eurocode 3. In: Bjorhovde R, Colson A, Zandonini R, editors. Connections in steel structures III. Proceedings of the Third International Workshop on Connections, Trento, Italy, May 8-31. 1995, p. 441-52.

[2] Simões da Silva LAP, Girão Coelho AM, Neto E. Equivalent post-buckling models for the flexural behaviour of steel connections. Comput Struct 2000;77:615-24.

[3] Eurocode 3, prEN 1993-1-8: 20xx, Part 1.8: Design of Joints, Eurocode 3: Design of Steel Structures, Final draft (corrected), February 2002. CEN, European Committee for Standardization, Brussels, 2002.

[4] Steenhuis M, Herwijnen F, Snijder HH. Safety concepts for ductility of joints. In: Leon R, Easterling WS, editors. Connections in steel structures IV. Proceedings of the Fourth International Workshop on Connections, Roanoke, VA, USA, October 22-25. 2000, p. 71-81.

[5] Jaspart JP. Recent advances in the field of steel joints - column bases and further configurations for beam-to-column joints and beam splices. Thèse présentée en vue de l'obtention du grade d'Agrégé de l'Enseignement Supérieur. Année Académique; 1996-1997.

[6] JCSS. Common unified rules fir different types of construction and materials. Joint Committee on Structural Safety, CEB Bulletin 116E, 1976.

[7] Simões da Silva L, Santiago A, Vila Real P. Post-limit stiffness and ductility of end-plate beam-tocolumn steel joints. Comput Struct 2002;80:515-31.

[8] Gioncu V, Mazzolani F. Ductility of seismic resistant steel structures. Spon Press; 2002.

[9] Ang A, Tang W. Probability concepts in engineering planning and design vols. 1-2. New York: Wiley; 1975-1984. 
[10] Simões da Silva LAP, Girão Coelho AM. A ductility model for steel connections. J Const Steel Res 2001;57:45-70.

[11] Cruz P, Simões da Silva L, Rodrigues D, Simões R. Database for the semi-rigid behaviour of beam-to-column connections in seismic regions. J Const Steel Res 1998;46(120):1-3.

[12] Weynand K. Sicherheits-und Wirtschaftlichkeitsuntersuchungen zur Anwendung nachgiebiger Anschlusse im Stahlbau. Shaker Verlag, D 82 (Diss. RWTH Aachen), Heft 35, Aachen, 1997. 